\title{
ASSESSMENT OF MYOCARDIAL LEFT VENTRICULAR FUNCTIONS USING 2D SPECKLE TRACKING IN NORMAL PREGNANT FEMALES IN COMPARISON TO NORMAL NON-PREGNANT FEMALES
}

\author{
By
Mohammad El-Sayed Nofal, Mohey El-Din Mansour Al-Abbady, Saad Ebrahim Deef-Allah EL-Zoghby and Ahmed Mohammed Salah El-Din Ahmed

Department of Cardiology, Faculty of Medicine, Al-Azhar University

Corresponding author: Mohammad El-Sayed Nofal,

E-mail: $\underline{\text { mohammad_nofal33@gmail.com }}$

\begin{abstract}
Background: While the hemodynamic changes occurring during pregnancy have been reasonably well characterized, the impact of pregnancy on cardiac contractile function has not been fully elucidated.

Objective: To assess myocardial left ventricular functions in normal pregnant females using 2D speckle tracking echocardiography in comparison to non-pregnant adult females.

Patient and methods: The study was a prospective observational study that was carried out at Cardiology Department, Al-Azhar University Hospitals throughout the period between August 2016 and July 2019. The study involved 15 healthy control unpregnant women in addition to 45 pregnant ladies (15 in each trimester). All the included subjects underwent thorough clinical examination, routine laboratory investigations, resting electrocardiogram (ECG), resting conventional trans-thoracic echocardiography, and speckle tracking echocardiography.

Results: The two groups showed no-significant difference between them in accordance with age, systolic, and diastolic blood pressure. Left ventricular (LV) internal dimensions at end diastole (LVEDD) had significantly higher values in the third trimester cases. Moreover, the control group had the lowest value among the study groups. No significant changes were detected in LVESD. LVEDV and LVESV showed a significant increase during pregnancy. All readings were significantly higher than controls. The two groups showed no significant difference between them in accordance with ejection fraction. Global longitudinal strain was significantly different between the study groups. It decreases from $20.73 \%$ in the first trimester down to 18.33 and $16.67 \%$ in the second and third trimesters respectively. Besides, two-, three-, and four-chamber strain showed the same changes as well.
\end{abstract}

Conclusion: Cardiac adaptation throughout normal pregnancy is characterized by LV longitudinal thickening reduction.

Keywords: Speckle Tracking Echocardiography; Left Ventricular Changes; Pregnancy; LV Longitudinal strain. 


\section{INTRODUCTION}

Speckle tracking represents a recent echocardiographic technique that evaluates the degree of myocardial strain throughout the cardiac cycle. In 2-D echocardiographic image, it can be estimated by automated calculation of the distance between speckles in a certain ventricular segment (D'Ascenzi et al., 2016).

Speckles are created by the irregular ultrasound reflection which could be tracked during the cardiac cycle. It provides two advantages; it is angle independent, and operator measurement errors are also decreased (Mirea et al., 2016).

Longitudinal, radial, and circumferential strains could all be measured by speckle tracking. These parameters are used as prognostic factors for left ventricular geometry and function (Longobardo et al., 2017).

Strain is a parameter that represents object deformation compared to its original shape. It is expressed as the percentage of change from the original dimension. Measuring strain via speckle tracking depends on differences in speckle velocity and distance throughout the cardiac cycle (Collier et al., 2017).

Positive values indicate myocardial lengthening, whereas negative values mean contraction. Cardiac myofibrils have a helical nature as they can be oriented in radial, circumferential and longitudinal planes. Strain with speckle tracking can measure both global and regional functions and also specifically identifies the affected myocyte group. Conversely, left ventricular ejection fraction can measure the global function only (Zacher et al., 2020).

The aim of the present study was to assess myocardial left ventricular functions in normal pregnant females using 2D speckle tracking echocardiography in comparison to nonpregnant adult females.

\section{PATIENTS AND METHODS}

The study was a prospective observational study that was carried out at Cardiology department, Al-Azhar University Hospitals throughout the period between August, 2016 and July 2019. The study involved 15 healthy control unpregnant women in addition to 45 pregnant ladies (15 in each trimester). Consecutive normal pregnant females referred to our Echo. Lab. from the prenatal care clinic were included in the current study.

On the contrary, cases with previous cardiac problems, gestational diabetes, and pregnancy induced hypertension, bad echocardiographic examinations were excluded.

Informed with consents were taken from all participants before the beginning of the study. In addition, the study was approved by the local ethical committee of Al-Azhar University.

All cases and controls underwent complete history taking, thorough clinical examination, resting ECG, and resting transthoracic echocardiography.

Patients underwent transthoracic echocardiography at admission using X 51 matrix array probe (frequency range 1.5- 


\section{ASSESSMENT OF MYOCARDIAL LEFT VENTRICULAR FUNCTIONS...}

\subsection{MHz) connected to Philips IE 33} machine (Philips healthcare, MA, USA). Patients were connected to single lead ECG, and images were attained when the cases were lying in left lateral position at end of expiration in accordance with the American society of Echocardiography recommendations.

All typical measurements were attained in the parasternal long-and short-axis views; apical 4-chamber, 2-chamber and apical long axis views.

STE with simultaneous ECG recording, 2D echocardiography images were obtained from apical window (to get AP4C, AP2C and AP3C views), and left parasternal window (to get short axis views at LV basal, mid and apical levels). Apical views were scanned with special care, because foreshortening affects the results of STE.

All images were obtained when the patient was instructed to hold his breath, and then it was stored in cine-loop format from three or more consecutive beats. We used a frame rate between 50 and 90 frames/s. All data were digitally saved for subsequent on-cart offline analysis (Phillips Medical Systems).

The GLS values were estimated after aortic valve closure had been identified visually, frame-by-frame, in the AP3C view.

SLS values were based on the American Society of Echocardiography 17-segment LV model (Lang et al., 2015). Segmental LS was calculated as the percentage of lengthening or shortening of each segment, and global longitudinal stain (GLS) was calculated as the average of regional strains.

Data analysis: The data were collected, coded, and subjected to analysis utilizing the SPSS version 22 for Windows ${ }^{\circledR}$. The data were examined for normal distribution utilizing the test of Shapiro Walk. Quantitative data were expressed as mean \pm SD (Standard deviation). One-way analysis of the variance was utilized to make comparison between $>2$ independent groups of normally distributed variables expressed as F. P value less than 0.05 was regarded significant.

\section{RESULTS}

There was no significant difference between the study groups regarding patient age $(p=0.164)$. The mean value of systolic blood pressure did not show significant difference between the 2 groups $(p=0.399)$. Like SBP, DBP did not show significant difference between the 2 groups $(p=0.347)$ (Table 1). 
Table (1): Age and blood pressure within the study groups

\begin{tabular}{|c|c|c|c|c|c|}
\hline Groups & $\begin{array}{c}\text { Group 1 } \\
\text { (control) } \\
\mathbf{N = 1 5}\end{array}$ & $\begin{array}{c}\text { Group 2 } \\
\text { (first } \\
\text { trimester) } \\
\mathbf{N = 1 5}\end{array}$ & $\begin{array}{c}\text { Group 3 } \\
\text { (second } \\
\text { trimester) } \\
\mathbf{N = 1 5}\end{array}$ & $\begin{array}{c}\text { Group 4 } \\
\text { (third trimester) } \\
\mathbf{N = 1 5}\end{array}$ & P value \\
\hline $\begin{array}{c}\text { Age } \\
\text { Mean } \pm \text { SD }\end{array}$ & $25.27 \pm 2.60$ & $23.47 \pm 2.29$ & $24.07 \pm 2.49$ & $23.60 \pm 2.13$ & 0.164 \\
\hline $\begin{array}{c}\text { SBP } \\
\text { Mean } \pm \text { SD }\end{array}$ & $111 \pm 10.7$ & $116 \pm 12.28$ & $110.33 \pm 9.54$ & $115.33 \pm 12.32$ & 0.399 \\
\hline $\begin{array}{c}\text { DBP } \\
\text { Mean } \pm \text { SD }\end{array}$ & $67 \pm 6.76$ & $71.33 \pm 7.43$ & $67 \pm 7.75$ & $68.67 \pm 7.90$ & 0.347 \\
\hline
\end{tabular}

DBP: diastolic blood pressure, SBP: systolic blood pressure.

Likewise, left ventricular end systolic dimension was not significantly different between the study groups. It had a mean of $28.53 \mathrm{~mm}$ in the control group, while it was $29.8,30.47$, and $29.87 \mathrm{ml}$ in the first, second, and third trimesters respectively $(\mathrm{p}=0.137)$.

When it comes to the left ventricular end diastolic dimension, it was evident that it had significantly higher values in the third trimester cases $(48.27 \mathrm{ml}-\mathrm{p}$ $<0.001)$. Moreover, the control group had the lowest value among the study groups $($ mean $=44.73 \mathrm{ml})$.

Left ventricular end systolic volume was significantly different between the study groups $(\mathrm{p}<0.001)$. Second and third trimester cases had the highest values compared to controls and first trimester cases. Nevertheless, first trimester cases had significantly higher value compared to controls.

Regarding left ventricular end diastolic volume, it was significantly different between the study groups $(\mathrm{p}<0.001)$. The third trimester group had significantly higher values compared to the other 3 groups $($ mean $=92.33 \mathrm{ml})$.

There was no significant difference between the study groups regarding ejection fraction $(\mathrm{p}=0.767)$ (Table 2$)$.

Table (2): Comparison of echocardiographic parameters within the study groups

\begin{tabular}{|l|c|c|c|c|c|}
\hline \multicolumn{1}{|c|}{ Groups } & $\begin{array}{c}\text { Group 1 } \\
\text { (control) } \\
\mathbf{N = 1 5}\end{array}$ & $\begin{array}{c}\text { Group 2 } \\
\text { (first } \\
\text { trimester) } \\
\mathbf{N = 1 5}\end{array}$ & $\begin{array}{c}\text { Group 3 } \\
\text { (second } \\
\text { trimester) } \\
\mathbf{N = 1 5}\end{array}$ & $\begin{array}{c}\text { Group 4 } \\
\text { (third } \\
\text { trimester) } \\
\mathbf{N = 1 5}\end{array}$ & P value \\
\hline $\begin{array}{l}\text { LVESD (mm) } \\
\text { Mean } \pm \text { SD }\end{array}$ & $28.53 \pm 1.92$ & $29.80 \pm 2.68$ & $30.47 \pm 2.17$ & $29.87 \pm 2.26$ & 0.137 \\
\hline $\begin{array}{l}\text { LVEDD (mm) } \\
\text { Mean } \pm \text { SD }\end{array}$ & $44.73 \pm 1.83$ & $47.40 \pm 2.50 \mathrm{a}$ & $47.93 \pm 2.74 \mathrm{a}$ & $48.27 \pm 1.44 \mathrm{a}$ & $<0.001$ \\
\hline $\begin{array}{l}\text { LVESV (ml) } \\
\text { Mean } \pm \text { SD }\end{array}$ & $25.80 \pm 1.97$ & $28.60 \pm 1.40 \mathrm{a}$ & $33.40 \pm 1.30 \mathrm{a}, \mathrm{b}$ & $33 \pm 1 \mathrm{a}, \mathrm{b}$ & $<0.001$ \\
\hline $\begin{array}{l}\text { LVEDV (ml) } \\
\text { Mean } \pm \text { SD }\end{array}$ & $79.07 \pm 9.49$ & $83.13 \pm 2.33 \mathrm{a}$ & $85.87 \pm 1.81 \mathrm{a}$ & $\begin{array}{c}92.33 \pm 4.65 \\
\mathrm{a}, \mathrm{b}, \mathrm{c}\end{array}$ & $<0.001$ \\
\hline $\begin{array}{l}\text { EF\% } \\
\text { Mean } \pm \text { SD }\end{array}$ & $65.47 \pm 3.93$ & $68 \pm 14.78$ & $65.67 \pm 4.03$ & $65.13 \pm 4.31$ & 0.767 \\
\hline
\end{tabular}

$\mathrm{P}=$ Inter group significance

a: significance in relation to group1 (control group)

b: significance in relation to group2 (first trimester group)

c: significance in relation to group3 (second trimester group)

EF: ejection fraction, LVESD: left ventricular end systolic dimension, LVEDD: left ventricular end diastolic dimension, LVESV: left ventricular end systolic volume, LVEDV: left ventricular end diastolic volume. 


\section{ASSESSMENT OF MYOCARDIAL LEFT VENTRICULAR FUNCTIONS...}

Four chamber longitudinal strain was significantly different between the study groups $(\mathrm{p}<0.001)$. Second and third trimester cases had significantly lower values compared to controls and first trimester cases.

Two-chamber longitudinal strain was statistically different between the study groups ( $\mathrm{p}<0.001)$. Pregnant cases had significant lower values compared to controls. Moreover, third trimester cases had significantly lower values compared to cases in the first trimester.

Three-chamber longitudinal strain in second and third trimester cases had significantly lower values compared to controls and first trimester cases.

Regarding global longitudinal strain, it was significantly different between the study groups $(\mathrm{p}<0.001)$. Both second and third trimester cases had significantly lower GLS values compared to first trimester cases and controls (Table 3).

Table (3): Comparison of longitudinal strain parameters within the study groups

\begin{tabular}{|l|c|c|c|c|c|}
\hline \multicolumn{1}{|c|}{ Groups } & $\begin{array}{c}\text { Group 1 } \\
\text { (control) } \\
\text { Variables }\end{array}$ & $\begin{array}{c}\text { Group 2 } \\
\text { (first } \\
\text { trimester) } \\
\mathbf{N = 1 5}\end{array}$ & $\begin{array}{c}\text { Group 3 } \\
\text { (second } \\
\text { trimester) } \\
\mathbf{N = 1 5}\end{array}$ & $\begin{array}{c}\text { Group 4 } \\
\text { (third } \\
\text { trimester) } \\
\mathbf{N = 1 5}\end{array}$ & P value \\
\hline $\begin{array}{l}\text { LS-4ch } \\
\text { Mean } \pm \text { SD }\end{array}$ & $-26.13 \pm 5.58$ & $-24.60 \pm 5$ & $-19.87 \pm 2.80 \mathrm{a}, \mathrm{b}$ & $-18.20 \pm 3.21 \mathrm{a}, \mathrm{b}$ & $<0.001$ \\
\hline $\begin{array}{l}\text { LS-2ch } \\
\text { Mean } \pm \text { SD }\end{array}$ & $-27.47 \pm 3.23$ & $-20.73 \pm 3.63 \mathrm{a}$ & $-19.67 \pm 3.64 \mathrm{a}$ & $-17.47 \pm 2.83 \mathrm{a}, \mathrm{b}$ & $<0.001$ \\
\hline $\begin{array}{l}\text { LS-3ch } \\
\text { Mean } \pm \text { SD }\end{array}$ & $-24.73 \pm 5.20$ & $-21.60 \pm 4.29$ & $-17.47 \pm 2.42 \mathrm{a}, \mathrm{b}$ & $-16.67 \pm 2.02 \mathrm{a}, \mathrm{b}$ & $<0.001$ \\
\hline $\begin{array}{l}\text { LS-GLS } \\
\text { Mean } \pm \text { SD }\end{array}$ & $-22.33 \pm 2.06$ & $-20.73 \pm 3.06$ & $-18.33 \pm 2.53 \mathrm{a}, \mathrm{b}$ & $-16.67 \pm 1.95 \mathrm{a}, \mathrm{b}$ & $<0.001$ \\
\hline
\end{tabular}

$\mathrm{P}=$ Inter group significance

a: significance in relation to group1 (control group)

b: significance in relation to group2 (first trimester group)

Ch: chamber, GLS: global longitudinal strain. LS: longitudinal strain.

\section{DISCUSSION}

We included 15 controls, in addition to 15 pregnant cases in each pregnancy trimester. Age was not a significant variable between our studies groups showed that no significant difference was reported regarding patient general characteristics (Sengupta et al., 2017).

In the current study, no significant changes were noticed regarding systolic blood pressure (SBP) between the study groups. Another study reported no significant difference between the included cases regarding SBP. Sengupta et al. (2017) Conversely, Sengupta and his associates reported that systolic blood pressure showed significant difference between the study groups. Besides, results showed that it was higher throughout the pregnancy trimesters compared to controls. However, that increase was statistically significant for the first and third trimesters only.

In our study, it was evident that LVEDD had significantly higher values in the third trimester cases. Moreover, the control group had the lowest value among the study groups. It increased steadily throughout pregnancy till reaching the highest level in the third trimester. In another study, LVEDD did not differ between controls, first, and second 
trimester cases. However, in the third trimester, it increased significantly which was significantly higher than controls and first trimester cases (Cong et al., 2015).

In the current study, no significant changes were detected in LVESD. Cong and his colleagues (2015) reported that LVESD was significantly greater in the third trimester in comparison with controls. Nevertheless, it was not significantly different from other pregnancy trimesters.

In the current study, LVEDV showed a significant increase during pregnancy. All these readings were significantly higher than controls. In another study, LVEDV significantly elevated throughout pregnancy. Hall et al. (2011) this could be elucidated by the fact that cardiac adaptations of the pregnant females throughout pregnancy are recognized to start around the fifth week. The increased volume of the circulating blood results in increasing the preload that appears in the elevated LVEDV.

In our study, LVESV increased significantly during pregnancy, and it was significantly greater than the subjects in the control group. Other authors reported that LVESV showed significant increase throughout pregnancy (Sengupta et al., 2017).

In our study, the study groups showed insignificant difference between them according to the ejection fraction.

In another study, although EF did not differ significantly between controls and first trimester cases, there was a significant decrease in the second and third trimester compared to the first one (Cong et al., 2015).
In another study, it was found a little decrease in LVEF throughout the $2^{\text {nd }}$ trimester that consequently increased in $3^{\text {rd }}$ trimester (Sengupta et al., 2017).

Regarding global longitudinal strain in the current study, it was significantly different between the study groups. It decreases from $20.73 \%$ in the first trimester down to 18.33 and $16.67 \%$ in the second and third trimesters respectively. Both second and third trimester cases had significantly lower GLS values compared to first trimester cases and controls. Besides, two-, three-, and four-chamber strain showed the same changes as well.

In another study, GLS showed significant decrease in pregnant females throughout the $1^{\text {st }}$ trimester and continued decreased all over the pregnancy and labor with lowest value in the 3rd trimester. Correspondingly, GCS showed also significant decrease all over the pregnancy in comparison with the subjects in the control group and deteriorated with the next trimesters (Sengupta et al., 2017). Several studies have assessed the systolic function of LV throughout pregnancy but have documented contradictory outcomes (Savu et al., 2012 and Estensen et al., 2013).

The majority of the previous studies have utilized the global indices of the ejection phase like LVEF or fractional shortening for this point. LVEF has been the most frequently utilized measure of the systolic function of $\mathrm{LV}$ in clinical practice, it shows some restrictions (Pfeffer et al., 2019).

Speckle tracking echocardiography (STE) gives better information about myocardial deformation and consequently, much greater insights into the mechanics 


\section{ASSESSMENT OF MYOCARDIAL LEFT VENTRICULAR FUNCTIONS...}

of the myocardium (Geyer et al., 2010 and Mor-Avi et al., 2011).

Savu et al. (2012) measured Doppler based LV segmental LS pregnant females. Furthermore, RS and CS were measured, but utilizing STE and only from 1 shortaxis view. It was documented that LS decreased throughout pregnancy, while RS and CS were still unchanged (the values of RS and CS were not documented though). On the other hand, technical restrictions (i.e. utilization of 2 dissimilar techniques for LV strain measurement.) prevent the generalization of these findings.

Cong et al. (2015) utilized 3D STE to evaluate the contractile function of the myocardium throughout pregnancy. They documented that all strain components and the overall LEVF decreased throughout pregnancy but increased to normal levels after labor. GLS decreased down from $21.32 \%$ in the first trimester down to 20.30 and 18.85 in the second and third trimesters respectively.

LS is mainly determined by the vertical sub-endocardial fibers that are more susceptible to pathological changes of myocardium. GLS is the 1st one to show impairment in the majority of the states of the disease. On the contrary, GRS and GCS are mainly decided by the subepicardial and mid-myocardial fibers which are arranged in radial pattern, and they get involved in late conditions. GRS may be strangely elevated throughout the initial disease course to compensate for the long-axis function loss (Sengupta et al., 2012 and 2013).

The contractile function impairment in certain direction is associated with compensatory alterations in the other directions. The GRS augmentation in a previous study (Sengupta et al., 2017) is consequently reliable with these observations and proposes that there was a significant cardiac adaptation which assisted maintaining typical ejection performance of the $\mathrm{LV}$ and provide the high hemodynamic requirements of pregnancy. This elucidates the cause by which the global LV function was still normal in spite of decreased longitudinal shortening in number of studies having pregnant females (Cong et al., 2015).

Furthermore, the GRS augmentation elucidates the way by which the higher stroke work of LV could be reached in spite of high afterload, that could not be elucidated by Cong et al. study where elevated stroke work took place despite a reduction in the entire strain components of LV and LVEF (Cong et al., 2015).

Our study has several limitations; first of all, the relatively small sample size. Therefore, more studies should be conducted in the future regarding the same issue. Moreover, we should have measured the same variables in an additional group including ladies in labor. This should be considered in the upcoming studies.

\section{CONCLUSION}

Throughout normal pregnancy, cardiac adaptation is characterized by LV longitudinal thickening decrease. The myocardial mechanical changes help to maintain left ventricular function within a normal range that can provide the high circulatory requirements during pregnancy and labor. 


\section{REFERENCES}

1. Collier P, Phelan $D$ and Klein A. (2017): A test in context: myocardial strain measured by speckle-tracking echocardiography. Journal of the American College of Cardiology, 69(8):1043-56.

2. Cong J, Fan T, Yang X, Squires JW, Cheng $G$ and Zhang L. (2015): Structural and functional changes in maternal left ventricle during pregnancy: a three-dimensional speckle-tracking echocardiography study. Cardiovascular Ultrasound, 13(1): 6-11.

3. D'Ascenzi F, Caselli S, Solari M, Pelliccia A, Cameli M and Focardi M. (2016): Novel echocardiographic techniques for the evaluation of athletes' heart: A focus on speckletracking echocardiography. European Journal of Preventive Cardiology, 23(4):437-46.

4. Estensen M, Beitnes J, Grindheim G, Aaberge L, Smiseth $O$ and Henriksen T. (2013): Altered maternal left ventricular contractility and function during normal pregnancy. Ultrasound in Obstetrics \& Gynecology, 41(6):659-66.

5. Geyer H, Caracciolo G, Abe H, Wilansky S, Carerj S and Gentile F. (2010): Assessment of myocardial mechanics using speckle tracking echocardiography: fundamentals and clinical applications. Journal of the American Society of Echocardiography, 23(4):351-69.

6. Hall ME, George EM and Grangerb JP. (2011): The Heart during
Pregnancy. Rev Esp Cardiol., 64(11): 1045-1050.

7. Lang RM, Badano LP, Mor-Avi V, Afilalo $J$, Armstrong $A$ and Ernande L. (2015): Recommendations for cardiac chamber quantification by echocardiography in adults: an update from the American Society of Echocardiography and the European Association of Cardiovascular Imaging. European Heart JournalCardiovascular Imaging, 16(3):23371.

8. Longobardo L, Suma V, Jain R, Carerj S, Zito $C$ and Zwicke DL. (2017): Role of two-dimensional speckle-tracking echocardiography strain in the assessment of right ventricular systolic function and comparison with conventional parameters. Journal of the American Society of Echocardiography, 30(10):937-46.

9. Mirea O, Duchenne J and Voigt JU. (2016): Recent advances in echocardiography: strain and strain rate imaging. F1000Research, 5: 78791.

10. Mor-Avi V, Lang RM, Badano LP, Belohlavek M, Cardim NM and Derumeaux G. (2011): Current and evolving echocardiographic techniques for the quantitative evaluation of cardiac mechanics: ASE/EAE consensus statement on methodology and indications endorsed by the Japanese Society of Echocardiography. European Journal of Echocardiography, 12(3):167-205. 


\section{ASSESSMENT OF MYOCARDIAL LEFT VENTRICULAR FUNCTIONS...}

11. Pfeffer MA, Shah AM and Borlaug BA. (2019): Heart Failure with Preserved Ejection Fraction in Perspective. Circulation Research, 124:1598-1617

12. Savu O, Jurcuţ R, Giuşcă $S$, Van Mieghem T, Gussi I and Popescu BA. (2012): Morphological and functional adaptation of the maternal heart during pregnancy. Circulation: Cardiovascular Imaging, 5(3):289-97.

13. Sengupta SP, Bansal M, Hofstra L, Sengupta PP and Narula J. (2017): Gestational changes in left ventricular myocardial contractile function: new insights from two-dimensional speckle tracking echocardiography. The International Journal of Cardiovascular Imaging, 33(1):69-82.

\section{Sengupta SP, Caracciolo G,} Thompson C, Abe $H$ and Sengupta PP. (2013): Early impairment of left ventricular function in patients with systemic hypertension: new insights with 2-dimensional speckle tracking echocardiography. Indian Heart Journal, 65(1):48-52.

15. Sengupta SP, Jaju R, Nugurwar A, Caracciolo $G$ and Sengupta PP. (2012): Left ventricular myocardial performance assessed by 2dimensional speckle tracking echocardiography in patients with sickle cell crisis. Indian Heart Journal, 64(6):553-8.

16. Zacher J, Blome I, Schenk $A$ and Gorr E. (2020): Cardiac adaptations in elite female football-and volleyballathletes do not impact left ventricular global strain values: a speckle tracking echocardiography study. The International Journal of Cardiovascular Imaging, 2020:1-12. 
تقييم وظائف عضلة البطينى الأيسر باستخدام تقنية التتبع النقطى ثنائية الأبعاد فى السيدات الحو امل الطبيعبين مقارنة

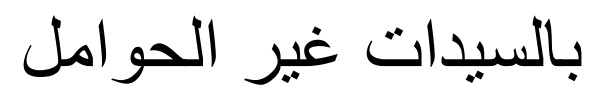

محمد العيد محمود نوفل، محي الدين منصور العبادي، سعد ابراهيم ضيف الله الزغبى،

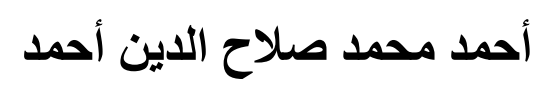

قسم القلب والأوعية الدموية، كلية الطب بنين، جامعة الأزهر

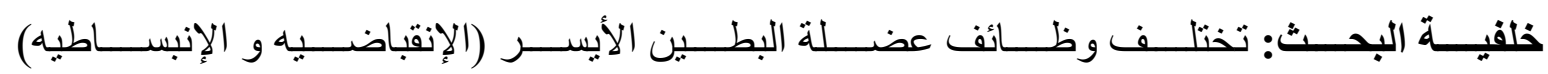

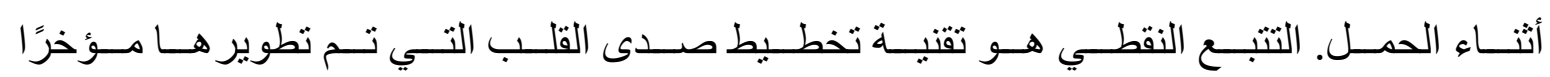

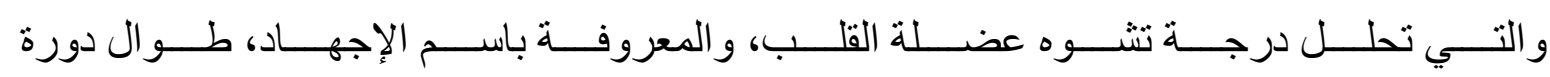

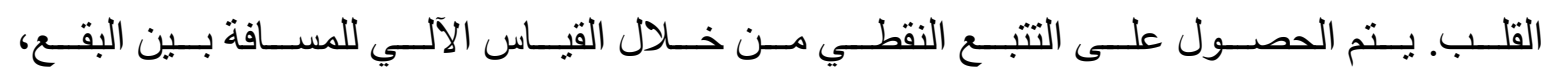

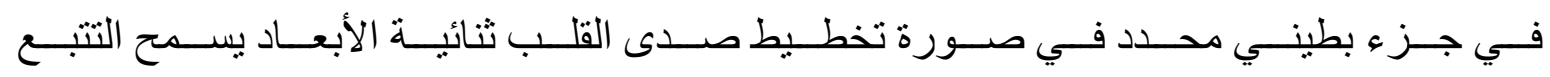

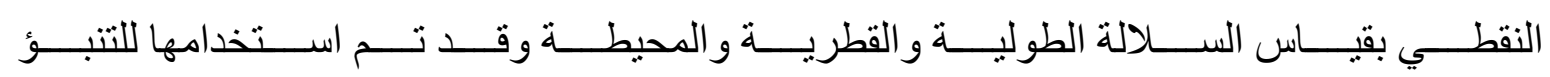
بالتغيرات في وظيفة البطين الأيسر و هندسته.

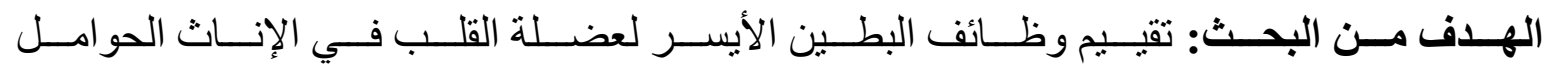

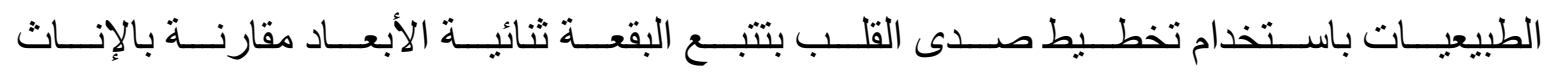

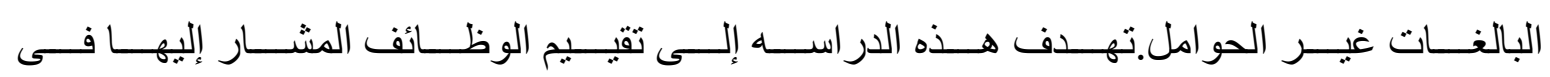

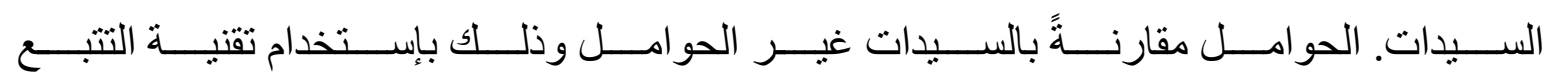

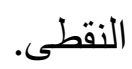

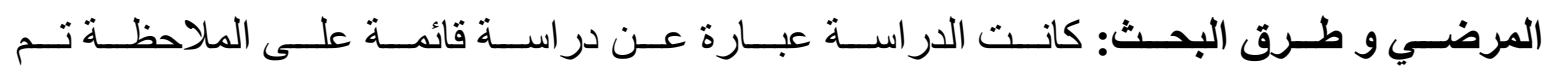

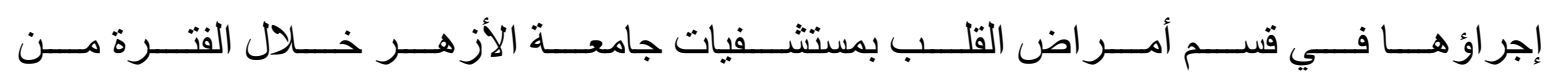

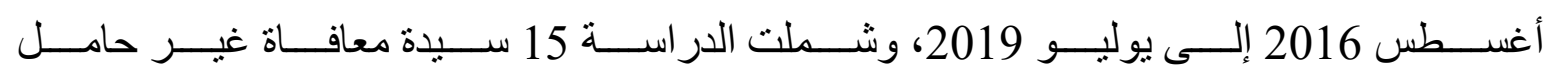

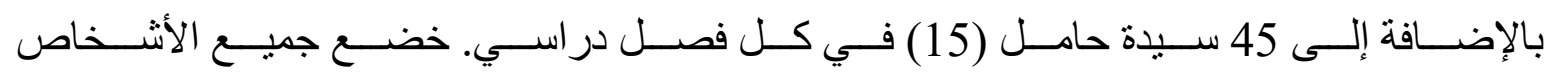

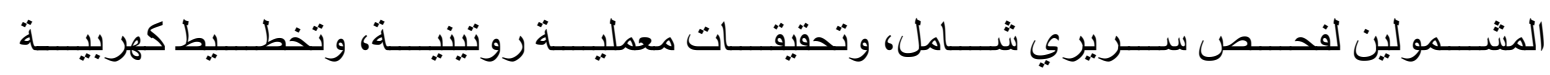

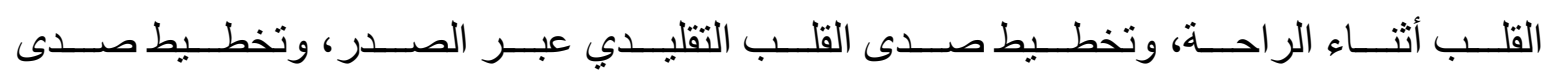
القلب بتتبع الرقطة. 


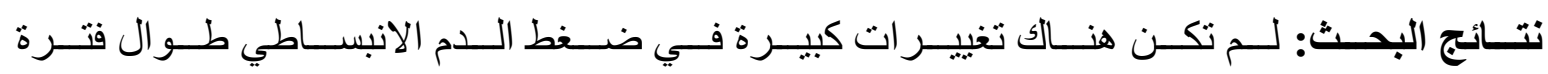

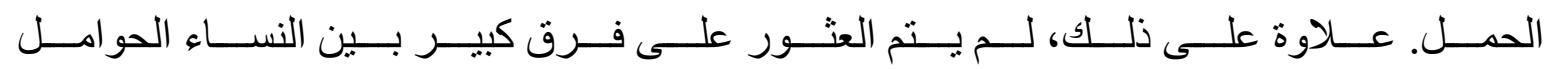

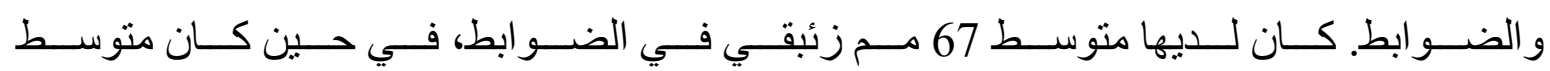

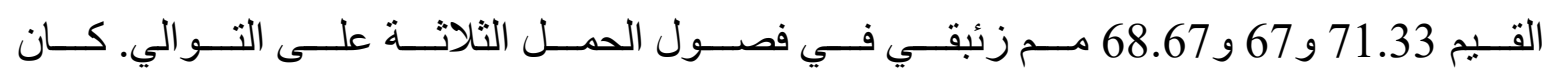

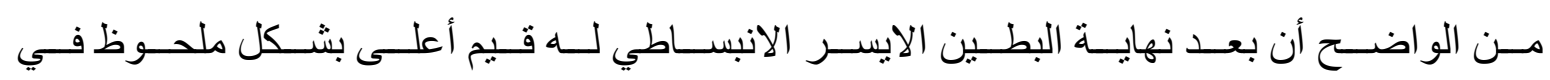

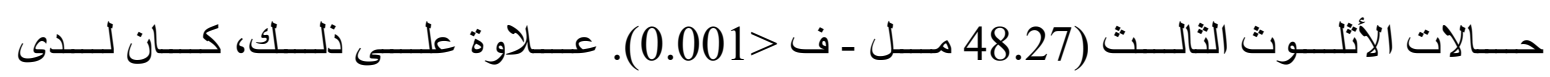

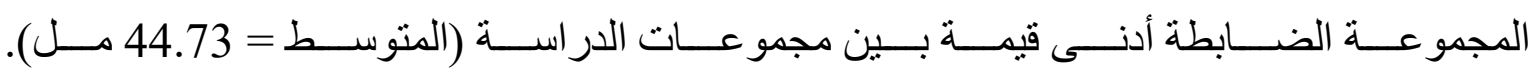

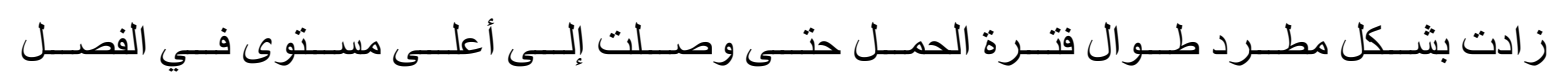

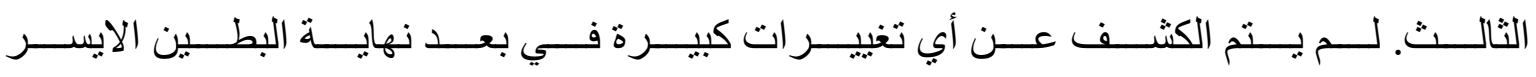

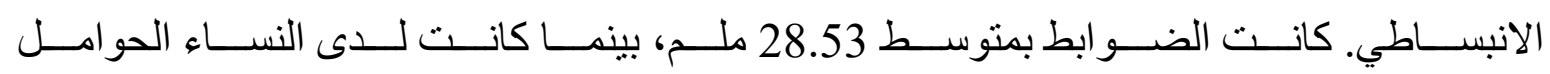

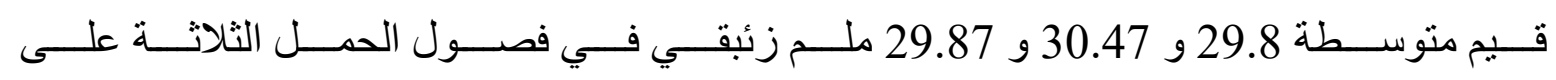

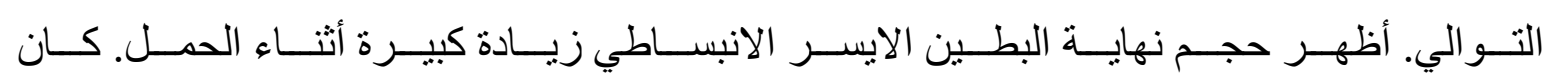

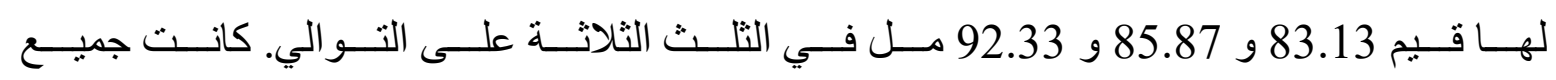

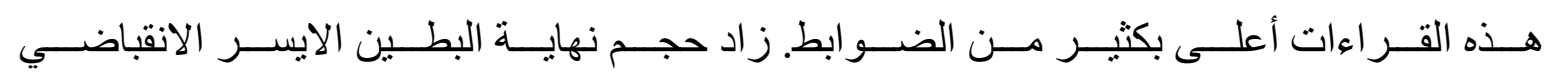

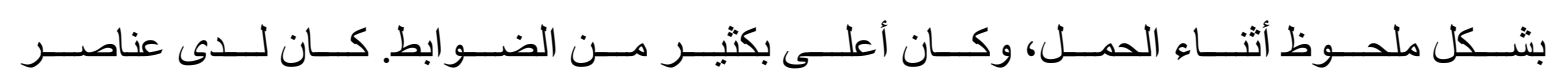

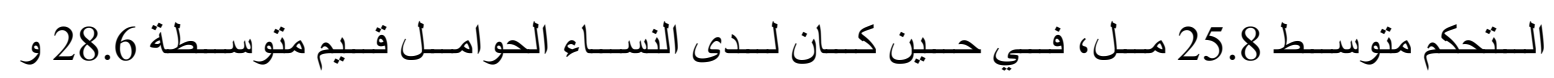
33.4 و 33 مل في فصول الحمل الثناثة على التو الي.

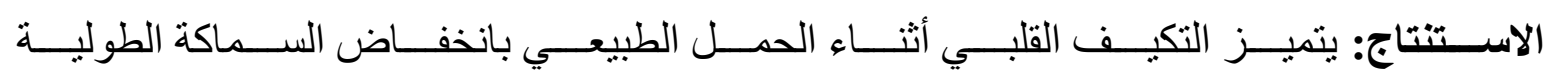

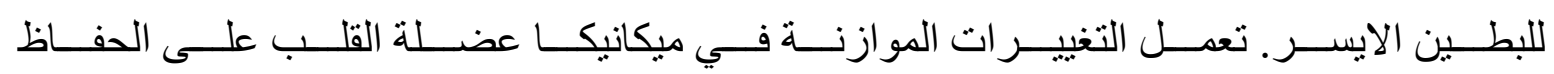

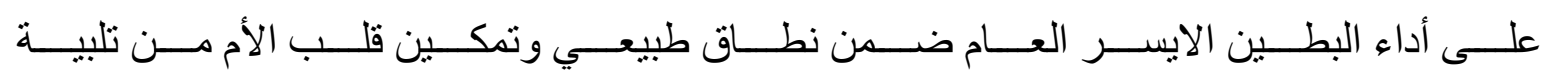
المتطلبات الديناميكية الدموية المتز ايدة للحمل و المخاض. الدئ. 